\title{
Correction to: The perplexity of catheter-directed thrombolysis for deep venous thrombosis: the approaches play an important role
}

\author{
Cheng Qian ${ }^{1}$. Guo-ping Chen ${ }^{1}$. Wen-sheng Lou ${ }^{1} \cdot$ Tao Wang $^{1} \cdot$ Ying-hao Li ${ }^{1}$
}

Published online: 25 September 2020

๑) Springer Science+Business Media, LLC, part of Springer Nature 2020

Correction to: Journal of Thrombosis and Thrombolysis https://doi.org/10.1007/s11239-020-02222-4

Publisher's Note Springer Nature remains neutral with regard to jurisdictional claims in published maps and institutional affiliations.

In the original version of the article, the first author's name was mentioned incorrectly. The correct name is "Cheng Qian". This has been corrected with this erratum.

The original article can be found online at https://doi.org/10.1007/ s11239-020-02222-4.

Guo-ping Chen

13851432561@163.com

1 Department of Interventional Radiology, Nanjing

First Hospital, Nanjing Medical University, Nanjing,

Jiangsu 210006, P.R. China 